\title{
Can Copper Be Used to Treat Foliar Phytophthora Infections in Pinus radiata?
}

\author{
Carol Rolando, ${ }^{1, \dagger}$ Chanatda Somchit, ${ }^{1}$ Martin K-F. Bader, ${ }^{2}$ Stuart Fraser, ${ }^{1}$ and Nari Williams ${ }^{1}$ \\ ${ }^{1}$ Scion, New Zealand Forest Research Ltd., Rotorua 3010, New Zealand \\ ${ }^{2}$ School of Science, Auckland University of Technology, Auckland 1010, New Zealand
}

\begin{abstract}
Red needle cast is a significant foliar disease of commercial stands of Pinus radiata caused by Phytophthora pluvialis in New Zealand. The effect of copper, applied as a foliar spray of cuprous oxide at a range of doses between 0 and $1.72 \mathrm{~kg} \mathrm{ha}^{-1}$, was investigated in two controlled trials with potted plants and in an operational trial with mature $P$. radiata. In all trials, lesions formed on needles after artificial exposure to the infecting propagules (zoospores) of $P$. pluvialis were used to determine treatment efficacy, with the number and/or length of lesions as the dependent variable. Results across all trials indicated that cuprous oxide was highly effective at reducing infection of $P$. radiata with $P$. pluvialis. Application rates equivalent to $\geq 0.65 \mathrm{~kg} \mathrm{ha}^{-1}$ significantly reduced infection levels relative to a control treatment, with foliar surface copper levels as low

as 13 to $26 \mathrm{mg} \mathrm{kg}^{-1}$ of needle tissue preventing infection. Greater copper content was associated with a reduction in the proportion of needles with $P$. pluvialis lesions, with the probability of lesions developing decreasing approximately $1 \%$ for every 1 unit (in milligrams per kilogram) increase in copper content. Over a 90-day period, surface copper content declined to $30 \%$ of that originally applied, indicating an approximate period of treatment efficacy of 3 months. Our findings highlight the potential of cuprous oxide for the control of red needle cast in $P$. radiata stands. Further information about the optimal field dose, timing, and the frequency of foliar cuprous oxide application is key to prevent infection and also reduce the build up of inoculum during severe outbreaks of this pathogen.
\end{abstract}

Copper has been applied as a fungicide in one form or another for controlling plant disease since at least the 18th century (Morton and Staub 2008). A variety of different forms of copper have been used for disease control, including copper hydroxide $\left[\mathrm{Cu}(\mathrm{OH})_{2}\right]$, copper oxychloride $\left[3 \mathrm{Cu}(\mathrm{OH})_{2} \cdot \mathrm{CuCl}_{2}\right]$, copper sulfate $\left[\mathrm{CuSO}_{4} \cdot 5 \mathrm{H}_{2} \mathrm{O}\right]$, and cuprous oxide $\left[\mathrm{Cu}_{2} \mathrm{O}\right]$ (MacBean 2016). Copper fungicides are foliar active, broad-spectrum preventative fungicides that have been effective in controlling a wide range of diseases, including those caused by fungi, oomycetes, and bacteria. On application of copper fungicides to foliage, solubilization of the initially insoluble copper compound occurs, which allows contact of copper ions with germinating spores and bacteria-disrupting enzyme systems and prevents further cellular and mycelial development (Franich and Wells 1975; Giannousi et al. 2013). Copper ions must be present on the crop before fungal spores germinate (MacBean 2016). After application, cycles of resolubilization and drying locally redistribute copper ions on individual leaves, improving ion-spore contact and disease control (Hislop and Cox 1970). Copper compounds generally adhere strongly to plant surfaces after application, even after rainfall events (Bulman and Carlson 2011; Franich and Wells 1975).

Phytophthora species are among the most serious pathogens in both native and production plant systems, with outbreaks often having devastating ecological and economic effects (Davis et al. 2014; Guenthner et al. 2001). Phytophthora pathogens are not true fungi, yet the sensitivity of Phytophthora species to copper fungicides is widely reported (Babadoost et al. 2015; Coelho et al. 2005; Lucero

${ }^{\dagger}$ Corresponding author: C. Rolando; carol.rolando@ scionresearch.com

Funding: This work was funded through the Needle Disease Strategy by the Ministry of Business, Innovation and Employment Strategic Science Investment Fund in partnership with the Forest Grower Levy Trust.

The author(s) declare no conflict of interest.

Accepted for publication 23 January 2019.

() 2019 The American Phytopathological Society et al. 2014). This active ingredient has been used to manage many Phytophthora species-related diseases, with primary success in controlling foliar infecting Phytophthora species (Coelho et al. 2005; Giannousi et al. 2013; Lawrence et al. 2017; Rolando et al. 2017a). Copper has also been used to control the foliar pathogen Phytophthora infestans (Mont.) de Bary, which causes late blight in plants belonging to the Solanaceae family (tomato, potato, eggplant, and peppers) (Giannousi et al. 2013). Although copper has been successfully applied to control ink disease of sweet chestnut (Castanea sativa Mill.) caused by the soilborne pathogens Phytophthora cambivora (Buismann Petri) and Phytophthora cinnamomi Rands (Coelho et al. 2005; Vettraino 2010), its use for the management of soilborne infections is limited and needs very careful consideration within natural ecosystems.

Phytophthora pluvialis Reeser, W.L. Sutton and E.M. Hansen is the causal agent of red needle cast in stands of Pinus radiata D. Don in New Zealand (Dick et al. 2014; Reeser et al. 2013). P. radiata accounts for $90 \%$ of plantation forest in New Zealand and as such, this disease has the potential to incur severe economic effects domestically (NZFOA 2016). Red needle cast was first observed in P. radiata stands on the east coast of New Zealand in late April 2008 (Dick et al. 2014). Since then, the disease has been reported from sites across both the North and South Islands, but with most damage observed in the center and the northeast coast of the North Island. Disease occurrence is often sporadic, with severe outbreaks occurring approximately every 3 years. Symptoms of red needle cast typically first appear in autumn (March to May) and are characterized by the development of olive-colored lesions on affected needles, which are frequently accompanied by resinous black bands. Affected needles quickly turn orange to brown, lending a reddish hue to the affected crown before being cast prior to the emergence of new needles in late spring. Studies have shown that severe defoliation events associated with red needle cast can reduce tree growth by up to $38 \%$ in the year after defoliation, with a further $10 \%$ loss in the next year provided that no further infection occurs.

Following the discovery of red needle cast in New Zealand, research was initiated to identify chemical options for management (Rolando et al. 2014, 2017a, 2017b). Early in vitro studies and in planta experiments identified copper as one of three active 
ingredients, along with metalaxyl-M and phosphite, that showed promise as a control agent for red needle cast (Rolando et al. 2017a). This was an important outcome from the initial screening studies because copper is already widely used in New Zealand for the control of Dothistroma needle blight, caused by the true fungus Dothistroma septosporum (Dorog.) M. Morelet, on P. radiata. Current industry practice is to apply cuprous oxide aerially in November (spring) to stands where an average of 10 to $20 \%$ of the total crown is affected by the disease. The fungicide is applied with a helicopter at an equivalent rate of $0.855 \mathrm{~kg} \mathrm{ha}^{-1}$ active ingredient, in 2 liters of oil per hectare made up to 5 liters per hectare with water (Bulman et al. 2013, 2016).

Following the initial in vitro and in planta studies, which were limited in the dose applied and also formulation, it was necessary to carry out further work to explore the efficacy of copper (applied as cuprous oxide) as a prophylactic treatment or management tool for red needle cast in $P$. radiata. This article details a combination of a pot trial and an operational field trial carried out to determine the response of $P$. pluvialis to cuprous oxide applied to $P$. radiata foliage as per the current formulation used by the New Zealand forest industry for control of Dothistroma needle blight. A further pot trial was carried out to evaluate the full dose response of $P$. pluvialis to cuprous oxide applied in oil to $P$. radiata foliage.

\section{Materials and Methods}

Experiment one: Copper applied at the industry standard and two times the industry standard. A $3 \times 3$ fully replicated factorial design was established using three copper (AG Copp 75; American Chemet Corporation) concentrations $\left(0 \mathrm{~kg} \mathrm{ha}^{-1}\right.$ control-oil only; $0.86 \mathrm{~kg} \mathrm{ha}^{-1}$ cuprous oxide, industry standard; or $1.72 \mathrm{~kg} \mathrm{ha}^{-1} \mathrm{cu}-$ prous oxide, two times the standard) and three potted (4.6-liter pots) $P$. radiata clones (A, B, and C). Each treatment comprised 15 single tree replications where the average height and diameter of the seedlings was 80 and $0.14 \mathrm{~cm}$, respectively. The three clones were all known to be susceptible to $P$. pluvialis. The cuprous oxide treatments all contained 2 liters of mineral oil (BP Dothi oil) made up to 5 liters of total volume with water. All treatments were applied using a conveyor belt track sprayer. A very fine droplet spectrum (American Society of Agricultural and Biological Engineers 2009) was produced by using an ULVA+ controlled droplet applicator (Micron Sprayers Ltd. 2014), calibrated to deliver 5 liters per hectare and droplets with a volume median diameter of approximately 60 to $70 \mu \mathrm{m}$. The $1.72 \mathrm{~kg} \mathrm{ha}^{-1}$ cuprous oxide treatment was achieved by doing two passes through the track sprayer, rather than decreasing the belt speed or altering the flow rate, as this would affect the droplet size. After treatment with cuprous oxide in October 2014, plants were placed in the Scion nursery in Rotorua, New Zealand, where they were exposed to ambient conditions. Plants were also drip irrigated for 3 months to prevent excessive drying out of the pots. Needles were sampled and exposed to $P$. pluvialis in detached needle assays at 7 and 84 days.

The protocol for conducting detached needle assays with $P$. pluvialis was described in Rolando et al. (2014, 2017a). Briefly, five fascicles were collected from each potted ramet and exposed to zoospores of $P$. pluvialis overnight. Following exposure, fascicles were placed on trays moistened with wet paper towels and incubated in a controlled environment $\left(17^{\circ} \mathrm{C}, 65\right.$ to $70 \%$ relative humidity, 14-h photoperiod) for 10 days. The needles within each fascicle were separated and the lesion number and length were assessed.

A subsample of the needles collected for the detached needle assays was submitted for determination of surface copper content. For each assessment, needles were bulked from replications 1 to 5 , 6 to 10 , and 11 to 15 , respectively. Approximately 2 g dry weight of each sample was used for the copper analyses. The needles were digested in 1:1 $10 \% \mathrm{HCl} /$ methanol solution and analyzed by atomic absorption spectroscopy. Each bulk sample was digested in triplicate.

Experiment two: Field trial using the operational copper treatment. Current industry standard copper treatments were applied in mid-November 2015 to three different $P$. radiata stands in the central North Island region of New Zealand, aged 4 years (Kinleith), 8 years (Te Manawa O Tuhoe [TMOT]), and 15 years (Waiotapu). Treatments consisted of cuprous oxide (AG Copp 75) applied in very fine droplets (using Micronair nozzles) by helicopter (Iroqois Bell) at $0.86 \mathrm{~kg} \mathrm{ha}^{-1}$ metal equivalents in 2 liters of mineral oil made up to 5 liters per hectare total volume with water (Baillie et al. 2017). Prior to treatment application, 20 random trees were selected and labeled at each site. Three branchlet subsamples were taken from each tree before ( 1 week) and after ( 1 month) treatment application to be used in detached needle assays with $P$. pluvialis. Each assay was carried out immediately after needle collection. For each assay, 10 fascicles were selected from each branchlet and dipped into sterilized pond water or a solution containing $P$. pluvialis zoospores overnight, after which they were placed in a controlled temperature room for 10 days as per standard detached needle assay protocols (Rolando et al. 2014, 2017a). After incubation for 10 days, the lesion number and length were assessed.

On the day of spraying, needle samples for determination of surface copper content were collected after spraying. Samples were collected from the 20 trees selected for the detached needle assay assessments and analyzed as described above.

Experiment three: Copper dose-response trial. Using the conveyor belt track sprayer (described above), copper (AG Copp 75) treatments $\left(0,0.22,0.43,0.65,0.86\right.$, and $1.72 \mathrm{~kg} \mathrm{ha}^{-1}$ cuprous oxide) representing application rates up to two times the recommended application rate were applied in oil (2 liters per hectare), made up to 5 liters per hectare total volume with water, to three commercial genotypes of $P$. radiata obtained from a local nursery. As a result of plant availability, these were not the same genotypes as the commercial clones used in experiment 1 . One-year-old ramets were lifted in November 2016 and potted in 4.6-liter pots; they were $29.6 \mathrm{~cm}$ tall on average, with a root collar diameter of $0.06 \mathrm{~cm}$ at the time of trial initiation in late March 2017. There were two control treatments, one that included spraying with water and oil only and another that did not receive any treatment (water or oil). During the application of each treatment, six steel plates $\left(115 \mathrm{~cm}^{2}\right)$ were placed on the conveyor belt to estimate the actual amount of copper applied (dose applied in kilograms per hectare). These were submitted to the laboratory where copper content was determined using atomic absorption spectroscopy.

Following treatment with copper, the potted ramets were placed into one of two fog chambers (inoculated or control) for 12 weeks,

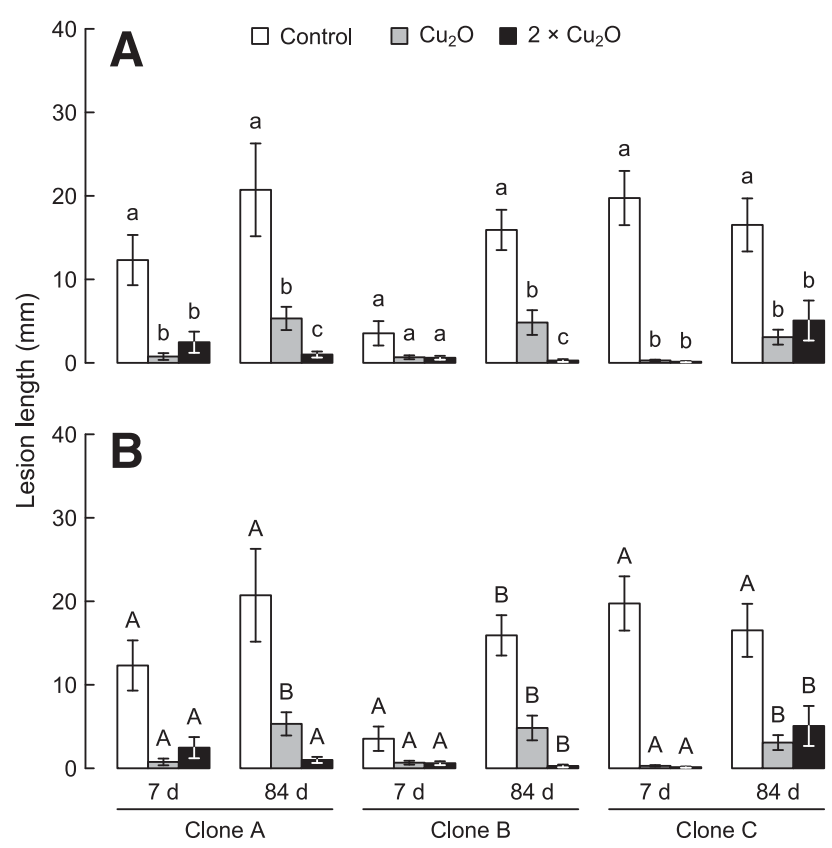

Fig. 1. A and B, Average lesion length per fascicle in Pinus radiata needles inoculated with Phytophthora pluvialis. $7 \mathrm{~d}=$ assessed 7 days after inoculation, $84 \mathrm{~d}=$ assessed 84 days after inoculation. A, Different lowercase letters indicate statistically significant differences between copper treatments within clone and assessment date. B, Different uppercase letters indicate statistically significant differences between assessment dates within copper treatment and clone (multiple comparison procedures using Tukey contrasts at $\alpha=0.05$ ). 
each with an identical experimental layout. There were six replications of each treatment in each chamber, with each replication consisting of three ramets (one of each clone). Plants were placed into the respective fog chambers 3 days prior to the first inoculation on 20 April 2016 (and exactly 1 week after spraying with copper). To initiate infection, plants were sprayed to run off with a suspension of $P$. pluvialis zoospores at $1 \times 10^{4}$ zoospores $\mathrm{ml}^{-1}$. To increase the likelihood of infection, $P$. pluvialis mycelial mats produced in a broth were evenly spread over fly mesh stretched $30 \mathrm{~cm}$ above the potted plants and left for $24 \mathrm{~h}$ with ongoing fogging to induce further zoospore release and opportunities for infection. Production of zoospores was previously described (Rolando et al. 2014, 2017a). Fog chamber environmental conditions were set at a 14-h/10-h day/night schedule, with fog applied for $1 \mathrm{~min}$ every $20 \mathrm{~min}$. The temperature was set at $17^{\circ} \mathrm{C}$. There were two inoculation events in the trial; the first

Table 1. Analysis of variance table of the final model used for experiment 1 showing the impact of the industry standard treatment and the two times the industry standard treatment on the size of Phytophthora pluvialis lesions on Pinus radiata needles

\begin{tabular}{lccrc}
\hline Parameter & $\begin{array}{c}\text { Numerator } \\
\text { df }\end{array}$ & $\begin{array}{c}\text { Denumerator } \\
\text { df }\end{array}$ & $\begin{array}{c}\boldsymbol{F} \\
\text { value }\end{array}$ & $\boldsymbol{P}$ value $^{\mathbf{z}}$ \\
\hline Intercept & 1 & 138 & 43.35 & $<0.001^{*}$ \\
Treatment & 2 & 138 & 30.01 & $<0.001^{*}$ \\
Clone & 2 & 138 & 1.89 & 0.155 \\
Date & 1 & 9 & 0.01 & 0.919 \\
Treatment $\times$ Clone & 4 & 138 & 15.26 & $<0.001^{*}$ \\
Treatment $\times$ Date & 2 & 138 & 22.16 & $<0.001^{*}$ \\
Clone $\times$ Date & 2 & 138 & 0.26 & 0.769 \\
Treatment $\times$ Clone $\times$ & 4 & 138 & 3.67 & $0.007^{*} *$ \\
$\quad$ Date & & & & \\
\hline
\end{tabular}

${ }^{\mathrm{z}}$ Significant values are denoted as follows: $* P<0.001$ and $* * P<0.01 . \mathrm{df}=$ degrees of freedom.

Table 2. Needle surface copper content at 7 and 84 days after treatment in experiment $1^{\mathrm{z}}$

\begin{tabular}{lcc}
\hline Treatment $\left(\mathrm{kg} \mathrm{ha}^{-\mathbf{1}}\right)$ & $\mathbf{7}$ days & $\mathbf{8 4}$ days \\
\hline Control & 0.0 & 0.0 \\
0.86 & $50.0 \pm 10.0$ & $20.0 \pm 0.00$ \\
1.72 & $150 \pm 50$ & $60 \pm 0.04$ \\
\hline
\end{tabular}

${ }^{\mathrm{z}}$ Data are presented as means \pm standard deviation (in milligrams per kilogram). was carried out a week after spraying (and 1 week before the first assessment), and the second, 7 weeks after the initial inoculation.

Plants were assessed for signs of infection at 1, 5, 8, and 12 weeks after the initial infection. At each assessment, three fascicles, each containing three needles, were randomly selected from each ramet and scored for the number of needles with at least one lesion caused by $P$. pluvialis (i.e., maximum score of 3 per fascicle). Foliage samples for the determination of the surface copper content were also submitted to the laboratory immediately after spraying with copper and at the 5-week and 12-week disease assessments (6 weeks and 13 weeks after spraying). For the first analysis, surface copper content was analyzed at three different scales: using the above-ground biomass, $2 \mathrm{~g}$ of needle tissue, or for a single fascicle only. All further samples used $2 \mathrm{~g}$ of needle tissue (which was standard laboratory practice).

Statistical analysis. For experiment one (copper applied at the industry standard and two times the industry standard), a linear mixedeffects model fitted by restricted maximum likelihood was used to analyze the lesion length data (Pinheiro et al. 2015; R Core Team 2016). The model contained copper treatment (control, standard copper, and copper applied at two times the industry standard), clone identity (A, B, and C), assessment date (7 or 84 days), and their interaction as fixed effects. The nested random term comprised assessment date nested in the ramet to reflect the repeated-measures nature of the data. Graphical model validation tools were used to test the underlying assumptions of variance homogeneity and normality (plots of standardized residuals versus fitted values and against all explanatory variables to evaluate variance patterns, quantile-quantile plots to assess the normality criterion). The data showed strong heteroscedascity, which was modeled using a combination of a constant plus power variance function structure (varConstPower), using the fitted values as the variance covariate and copper treatment as the grouping variable to allow for stratified variance modeling. The significant copper treatment $\times$ clone $\times$ assessment date interaction was followed up applying a multiple-comparisons procedure using Tukey contrasts (Hothorn et al. 2008; R Core Team 2016).

For experiment two (field trial testing operational copper treatment), a generalized least squares model fitted by restricted maximum likelihood was used to analyze the lesion lengths resulting from $P$. pluvialis inoculation ( $\mathrm{R}$ version 3.3.0, $\mathrm{R}$ Core Team 2016; R-package nlme, Pinheiro et al. 2015). The model comprised site (Kinleith, TMOT, and Waiotapu), spray (pre- and postcopper aerial spray), and inoculation treatment (control $=$ sterilized pond water, pathogen $=P$. pluvialis) and all interactions as explanatory variables. Graphical model validation tools were used to assess the underlying assumptions of variance homogeneity and normality

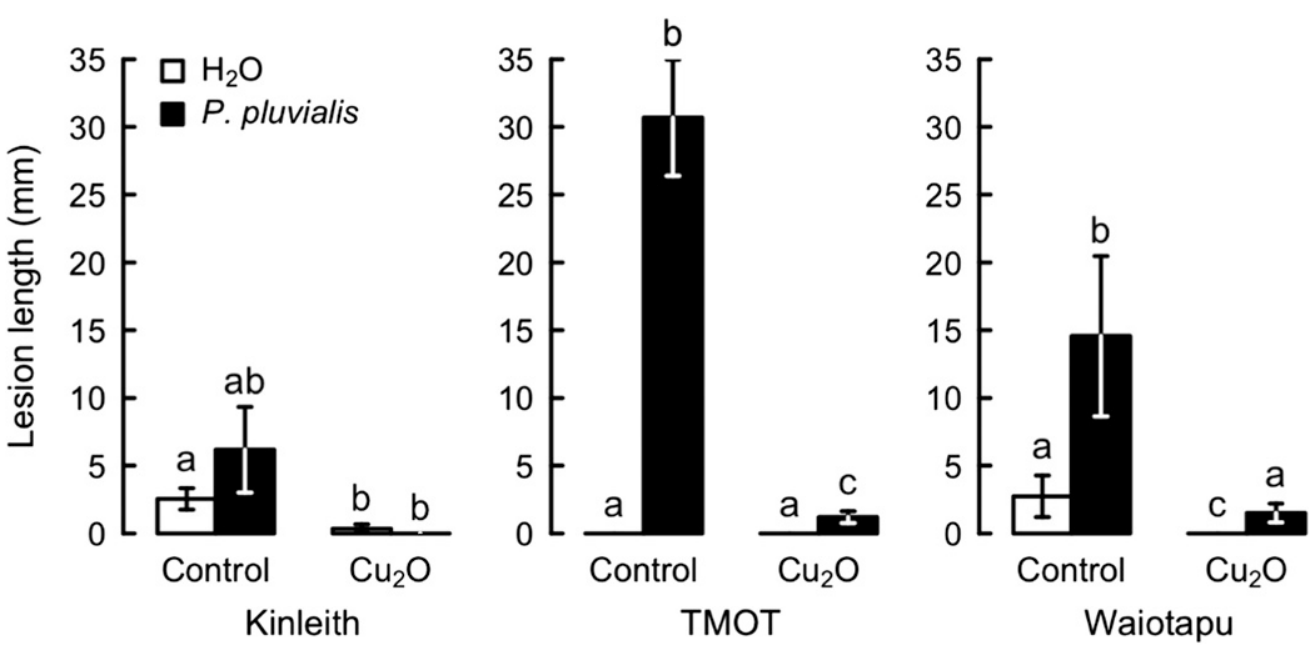

Fig. 2. Average lesion length in Pinus radiata fascicles collected either before (control) or 1 month after aerial copper spray application (Cu) and inoculated with Phytophthora pluvialis. Spray applied at three sites, with 20 trees assessed per site. Different lowercase letters indicate statistically significant $(P<0.05)$ differences within sites (based on a multiple comparison procedure using Tukey contrasts following the significant site $\times$ spray $\times$ inoculation interaction). TMOT $=$ Te Manawa $O$ Tuhoe. 
(plots of the standardized residuals versus fitted values and against all predictors, quantile-quantile plots). Variance heteroscedasticity was detected and accounted for by incorporating a constant variance structure using spray and inoculation treatment as variance covariates, allowing for stratified variance modeling. A significant three-way interaction term was sliced using a multiple comparison procedure with Tukey contrasts (R-package multcomp, Hothorn et al. 2008). The slicing was performed in two ways, allowing the comparisons between (i) the pathogen treatment levels within copper treatment levels at each site (i.e., $\mathrm{H}_{2} \mathrm{O}$ versus $P$. pluvialis within "control" and within " $\mathrm{Cu}_{2} \mathrm{O}$ " at each site) and (ii) between the copper treatment levels within the pathogen treatment levels at each site (i.e., "control" versus " $\mathrm{Cu}_{2} \mathrm{O}$ " within the $\mathrm{H}_{2} \mathrm{O}$ control plants and within the $P$. pluvialis-infected plants at each site). The resulting $P$ values were corrected for multiple testing using the Benjamini and Hochberg (1995) method.

For experiment three (copper dose-response trial), generalized linear mixed models (GLMMs) were used to investigate the efficacy of cuprous oxide dose (in kilograms per hectare) on the proportion of $P$. pluvialis lesions (out of nine needles) present on the selected needles (assuming a binomial error and logit link). The fixed effect variables were "inoculation treatment," "cuprous oxide dose," and the interaction between these two explanatory variables. Ramets nested in "replications" in "inoculation treatment" were included as a random effect. Graphical tools such as the Pearson residual plots were used to test for model validation. Overdispersion occurred and was modeled using a beta binomial GLMM (Zuur et al. 2009). The model parameters were estimated using Laplace approximation. Model selection for the fixed effect terms was based on backward selection using the Akaike information criterion and likelihood ratio tests (Zuur et al. 2009). The model was fitted using the $\mathrm{R}$ glmmADMB package (Skaug et al. 2015) and analyzed separately for each time period (week 1, 5, 8, and 12 assessments). Because no significant difference in lesion number was found between the two application control treatments, these were combined for all further analyses.

There was a significant response at week 5 to applied cuprous oxide dose (in kilograms per hectare) as assessed in the proportion of sampled needles with lesions of $P$. pluvialis. We used the surface copper content of foliage assessed immediately after spraying of copper, and at the time of first inoculation, to determine the relationship between foliar copper content at the time of inoculation and presence of $P$. pluvialis at week 5. A quasibinomial GLMM was performed using R-Mass (Ripley et al. 2015) for this analysis, with model checks and validation carried out as described above.

\section{Results}

Experiment one: Copper treatments applied at the industry standard and two times the industry standard. In the detached needle assays, the control developed pronounced lesions, on average between 12 and $23 \mathrm{~mm}$ long per fascicle (Fig. 1). Both copper treatments largely suppressed lesion development but this effect varied with clone and time. There was a significant interaction between copper treatment, clone, and assessment date (Fig. 1; Table 1). This interaction was caused by clone $\mathrm{B}$, for which there was no significant effect of the copper treatment on lesion length at 7 days, a result largely dependent on the small lesions that developed on the control needles. Copper dose $\left(0.844 \mathrm{~kg} \mathrm{ha}^{-1}\right.$ or $\left.1.76 \mathrm{~kg} \mathrm{ha}^{-1}\right)$ had no effect on lesion development at 7 days. In two of the three $P$. radiata pine clones (A and B), double the standard copper treatment proved to be a significant improvement over the standard application 84 days after inoculation (Fig. 1). It is likely that surface copper levels remained above the threshold levels for infection to occur in this treatment.

Seven days post-application, the copper recovery from the needle surface indicated copper levels in the two times the industry standard treatment (1.76 $\mathrm{kg} \mathrm{ha}^{-1}$ cuprous oxide) to be approximately three times more than that in the standard treatment $\left(0.86 \mathrm{~kg} \mathrm{ha}^{-1}\right.$ cuprous oxide) (Table 2). After 84 days of exposure to overhead irrigation and natural elements, very little of the original applied copper was still

Table 3. Results from model comparison procedures using the beta binomial generalized linear mixed models for the proportion of Phytophthora pluvialis lesions in response to copper dose (backward selection using the Akaike information criterion and likelihood ratio tests) ${ }^{\mathrm{z}}$

\begin{tabular}{lcccc}
\hline Dropped term & AIC & df & LR & P value \\
\hline None & 276.84 & & & \\
Room $\times$ cuprous oxide dose & 273.89 & 5 & 6.87 & 0.230 \\
Room & 270.76 & 1 & 0.17 & 0.676 \\
Cuprous oxide dose & 268.94 & 5 & 28.30 & $<0.001^{*}$ \\
\hline
\end{tabular}

${ }^{\mathrm{z}} \mathrm{AIC}=$ Akaike information criterion, $\mathrm{df}=$ degrees of freedom, and LR, likelihood ratio test. Significant values are denoted as follows: ${ }^{*} P<0.001$.

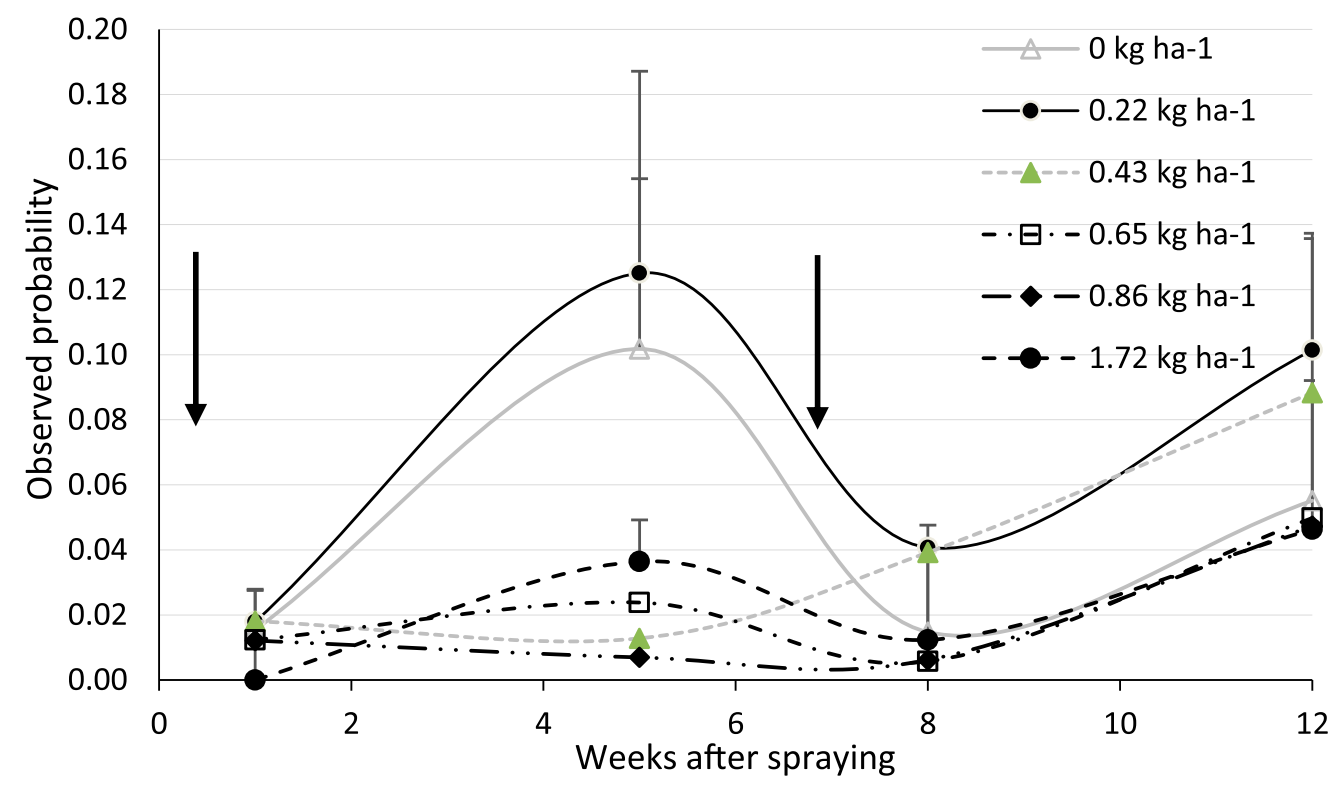

Fig. 3. Predicted incidence of Phytophthora pluvialis lesions at the week 1, 5, 8, and 12 assessments in response to cuprous oxide dose (in kilograms per hectare) for the duration of the trial. Bars indicate the standard error and arrows indicate inoculation days. 
present on the needle surface, yet this was sufficient to suppress lesion development in the detached needle assay (for both treatments).

Experiment two: Field trial using operational copper treatment. Prior to the application of the operational copper treatment $(0.86 \mathrm{~kg}$ $\mathrm{ha}^{-1}$ cuprous oxide in oil), $P$. radiata needles treated with sterilized pond water showed minimal lesion development across sites, while exposure of needles to $P$. pluvialis in the detached assay resulted in substantial lesion development (Fig. 2). This initial sampling established the baseline susceptibility of the trees to infection with $P$. pluvialis. The length of the lesions, however, differed by site. This could be attributed to a difference in susceptibility in the genotypes planted at each site or stand age or needle physiology.

Needles collected 1 month after aerial application of copper oxide showed suppressed lesion development relative to the prespray samples at all three sites (Kinleith, TMOT, and Waiotapu) (Fig. 2). Suppression was 100, 96, and 90\% at Kinleith, TMOT, and Waiotapu, respectively. Together these findings produced a significant site $\times$ spray $\times$ inoculation interaction (likelihood ratio statistic $[\mathrm{L}]=$ $14.78,2$ degrees of freedom, $P<0.001)$. Surface copper content of needles just after spraying was $26.5,22.0$, and $13.5 \mathrm{mg} \mathrm{kg}^{-1}$, respectively.

Table 4. Results from the beta binomial generalized linear mixed models for the proportion of Phytophthora pluvialis in the copper dose-response trial ${ }^{\mathrm{Z}}$

\begin{tabular}{lcccc}
\hline Parameter & Estimate & $\begin{array}{c}\text { SE of the } \\
\text { estimate }\end{array}$ & $\begin{array}{c}z \\
\text { statistic }\end{array}$ & $\boldsymbol{P}$ value \\
\hline $\begin{array}{l}\text { Fixed effects } \\
\text { Intercept }\end{array}$ & -2.50 & 0.426 & -5.88 & $<0.001^{*}$ \\
$\begin{array}{c}\text { Cuprous oxide dose } \\
\left(\mathrm{kg} \mathrm{ha}^{-1}\right)\end{array}$ & & & & \\
0.22 & 0.07 & 0.364 & 0.20 & 0.845 \\
0.43 & -1.56 & 0.586 & -2.67 & $<0.01^{* *}$ \\
0.65 & -1.20 & 0.525 & -2.29 & $<0.05^{* * *}$ \\
0.86 & -0.87 & 0.458 & -1.91 & 0.055 \\
1.72 & -1.65 & 0.644 & -2.57 & $<0.05^{* * *}$ \\
Random effects & & & & \\
$\quad$ Random intercept & $\begin{array}{c}\text { Estimated } \\
\text { variance of } 1.32\end{array}$ & & & \\
\hline
\end{tabular}

${ }^{z}$ Models included ramets, nested in "replications" in "inoculation treatment," as a random effect. Significant values are denoted as follows: $* P<0.001$, $* * P<0.01$, and $* * * P<0.05$.
Experiment three: Dose-response trial. Following inoculation, the greatest numbers of $P$. pluvialis lesions were observed at the week 5 assessment, followed by the week 12 assessment (Fig. 3). Both of these assessments were conducted 5 weeks after an inoculation. Lower numbers of lesions were scored for the assessments carried out in weeks 1 and 8 , each 1 week after an inoculation. This result may reflect that each inoculation event triggered one cycle of disease that took around 3 to 5 weeks to fully express but which did not progress (i.e., become polycyclic) or that infected needles were cast and not scored.

There was no statistical evidence of an effect of cuprous oxide on symptom expression at weeks 1,8 , and 12 . A statistically significant effect of dose (applied in kilograms per hectare) on infection level was observed in week 5 (Tables 3 and 4). The threshold for a significant reduction in infection at the week 5 assessment fell between the 0.22 and $0.43 \mathrm{~kg} \mathrm{ha}^{-1}$ copper treatments, equating to between $\sim 30$ to $\sim 60 \mathrm{mg} \mathrm{kg}^{-1}$ of surface copper content (either whole plant, 2-g sample, or one fascicle only) at the time of infection (Fig. 4; Table 5). Despite this reduction in the amount of surface copper, the infection level at week 5 was reduced by about $90 \%$ in contrast to both the control and $0.22 \mathrm{~kg} \mathrm{ha}^{-1}$ dose. There was no significant dose response at the week 12 assessment (Fig. 3). Surface foliar copper content determined at the week 5 assessment was between 26 and $60 \mathrm{mg} \mathrm{kg}^{-1}$ of copper on all treatments except the highest dose, where content was still $>100 \mathrm{mg} \mathrm{kg}^{-1}$ (Fig. 4). The second inoculation was carried out 7 weeks after spraying when copper would have been at or just below these levels, and possibly still high enough to prevent infection. Levels of surface copper had declined to $\leq 60 \mathrm{mg} \mathrm{kg}^{-1}$ for all treatments by the final assessment at week 12 (Fig. 4).

Analysis of the proportion of lesions assessed at week 5 in relation to surface copper content at the time of spraying (Table 5) indicated a highly significant effect of foliar surface copper content on the proportion of $P$. pluvialis lesions $(P<0.01)$. Greater surface copper levels were associated with a reduction in the proportion of needles with $P$. pluvialis lesions, with the probability of lesions developing decreasing approximately $1 \%$ for every 1 -unit increase in copper content (in milligrams per kilogram) (Fig. 5).

\section{Discussion}

All of the trials described provide strong evidence that cuprous oxide is effective at reducing symptoms of red needle cast on $P$. radiata. The amount of copper present on the surface of mature $P$. radiata foliage after operational application of cuprous oxide

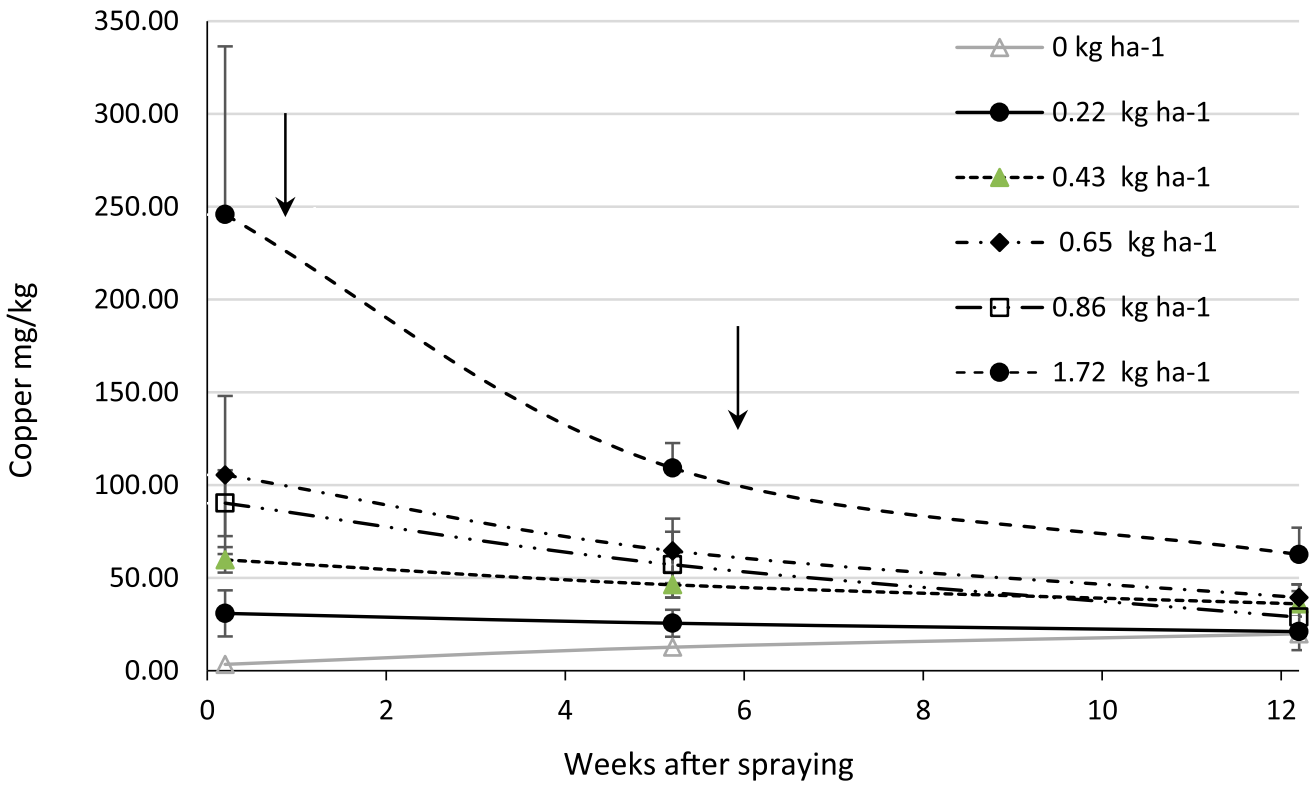

Fig. 4. Needle surface copper content determined by atomic absorption spectroscopy in experiment 3 . Arrows indicate inoculation events. 
in November for control of Dothistroma needle blight is around 20 to $30 \mathrm{mg} \mathrm{kg}^{-1}$ (Bulman and Carlson 2011; Gilmour and Noorderhaven 1973), as shown for the foliage samples collected shortly after spraying in the operational trial (experiment 2). This surface copper content is substantially lower than the surface levels of copper detected in the dose-response trial (experiment 3 ), where equivalent rates of cuprous oxide were applied to the foliage $\left(0.86 \mathrm{~kg} \mathrm{ha}^{-1}\right)$, and is also below the threshold of sensitivity identified in the same trial for prevention of $P$. pluvialis infection, estimated at between 30 and $50 \mathrm{mg} \mathrm{kg}^{-1}$. The detached needle assay carried out 1 month after spraying in the operational spray trial indicated high levels of efficacy against infection with $P$. pluvialis despite the lower levels of surface copper present on these needles shortly after spraying (13 to $26 \mathrm{mg} \mathrm{kg}^{-1}$ of copper). Lower levels of active ingredient on the surface of mature tree foliage than potted clones for the same application rate would be expected as a result of the differences in tree size and leaf area; however, the differential response does raise questions as to the minimum foliar surface copper content required to prevent infection of $P$. radiata with $P$. pluvialis in situ. Does $P$. pluvialis have a similar sensitivity to copper as $D$. septosporum? Relative sensitivities of the different pathogens would need to be confirmed, as well as whether the application rate of $0.86 \mathrm{~kg} \mathrm{ha}^{-1}$ cuprous oxide will be effective in the long term for management of red needle cast.

Research into Dothistroma needle blight indicated that the copper acted against the pathogen in two ways (Franich 1988). First, copper deposits on conifer needles dissolved slowly in water distributing copper ions across the needle surface, thereby killing spores released during rainfall events and also protecting foliage from new infections. The life cycle of $P$. pluvialis, an oomycete, is quite different from that of D. septosporum, an ascomycete. Fruit bodies are not

Table 5. Amount of surface copper per plant, 2-g sample, and fascicle at first sampling after spraying, as well as the amount of copper detected on calibration plates collected during spray operation

\begin{tabular}{lcccc}
\hline $\begin{array}{l}\text { Treatment } \\
\left(\mathbf{k g ~ h a}^{-\mathbf{1}}\right)\end{array}$ & $\begin{array}{c}\text { Plates } \\
\left(\mathbf{k g ~ h a}^{-\mathbf{1}}\right)\end{array}$ & $\begin{array}{c}\text { Fascicle } \\
\left(\mathbf{m g ~ k g}^{-1}\right)\end{array}$ & $\begin{array}{c}\mathbf{2 - g} \text { sample } \\
\left(\mathbf{m g ~ k g}^{-1}\right)\end{array}$ & $\begin{array}{c}\text { Whole plant } \\
\left(\mathbf{m g ~ k g} \mathbf{~ k g}^{-1}\right)\end{array}$ \\
\hline 0 & 0 & $5.3 \pm 1.6$ & $3.4 \pm 0.9$ & $2.1 \pm 0.4$ \\
0.22 & 0.30 & $30.9 \pm 5.7$ & $30.9 \pm 12.4$ & $20.6 \pm 6.3$ \\
0.45 & 0.39 & $79.0 \pm 38.9$ & $59.7 \pm 22.8$ & $54.8 \pm 3.2$ \\
0.65 & 0.68 & $89.9 \pm 58.8$ & $102.5 \pm 25.8$ & $68.7 \pm 14.4$ \\
0.86 & 0.65 & $83.2 \pm 69.2$ & $90.3 \pm 42.6$ & $75.2 \pm 18.4$ \\
1.72 & 1.47 & $322.2 \pm 187.4$ & $245.8 \pm 90.7$ & $197.8 \pm 42.7$ \\
0 & 0 & $6.1 \pm 1.6$ & $3.5 \pm 0.6$ & $1.2 \pm 0.2$ \\
\hline
\end{tabular}

produced by $P$. pluvialis (or other Phytophthora species). Under wet conditions, transient hyphae will grow out onto the needle surface through stomata and produce sporangia, which give rise to infective zoospores that disperse in water on the needle surface $(\mathrm{N}$. Williams, personal communication) and are presumed to spread in water splash based on demonstrated dispersal in similar systems. Despite this difference, copper is likely to have similar effects on both infection and sporulation by $P$. pluvialis to those described for $D$. septosporum. Copper on the needle surfaces will kill zoospores of $P$. pluvialis released during wet conditions, reducing infection. Copper on needle surfaces will likely also reduce sporulation by inhibiting the growth of hyphae out of the needles and the production of sporangia. A previous study demonstrated the inhibitory effect of copper on $P$. pluvialis mycelial growth in vitro (Rolando et al. 2017a), and copper has been shown to be effective in inhibiting Phytophthora growth in many systems and for many years (Halsall 1977).

Franich (1988) also showed that copper prevented fruiting bodies from producing and releasing spores. Data on the epidemiology of red needle cast indicate that inoculum is present from around autumn to early summer, with detection more frequent after periods of rainfall (Hood et al. 2017). High incidences of red needle cast result from polycyclic epidemics, where more than one cycle of infection occurs in any one season with the intensity of the epidemic dependent on the rate of infection in each cycle and the amount of initial inoculum (Hood et al. 2017). As with the management of Dothistroma needle blight, spraying with a copper fungicide at critical times will control the disease by stopping spore production, particularly during the production of primary inoculum at the start of an outbreak. Several studies have shown that copper inhibits mycelial growth of Phytophthora in vitro (Coelho et al. 2005; Lucero et al. 2014; Rolando et al. 2017a). Copper ions were also found to be inhibitory to sporangial production of Phytophthora and zoospores at a concentration of $10^{-7} \mathrm{M}$ (Coelho et al. 2005). Epidemiological results obtained thus far suggest that with $P$. pluvialis, a fungicidal spray treatment may be effective if applied during autumn (March) as temperatures begin to cool, with possibly a second spray later in the season (Hood et al. 2017). The efficacy of such a regime in the field is yet to be determined.

Almost all data collected on the persistence of copper indicate that 3 months is common (Bulman and Carlson 2011; Gilmour and Noorderhaven 1973), with surface residue levels decreasing in the order of $80 \%$ of the initial application concentrations in this time frame. Such observations were confirmed in this study, where both pot trials showed copper levels reducing to $\sim 30 \%$ of the original amount applied over a period of roughly 90 days. This would support the notion

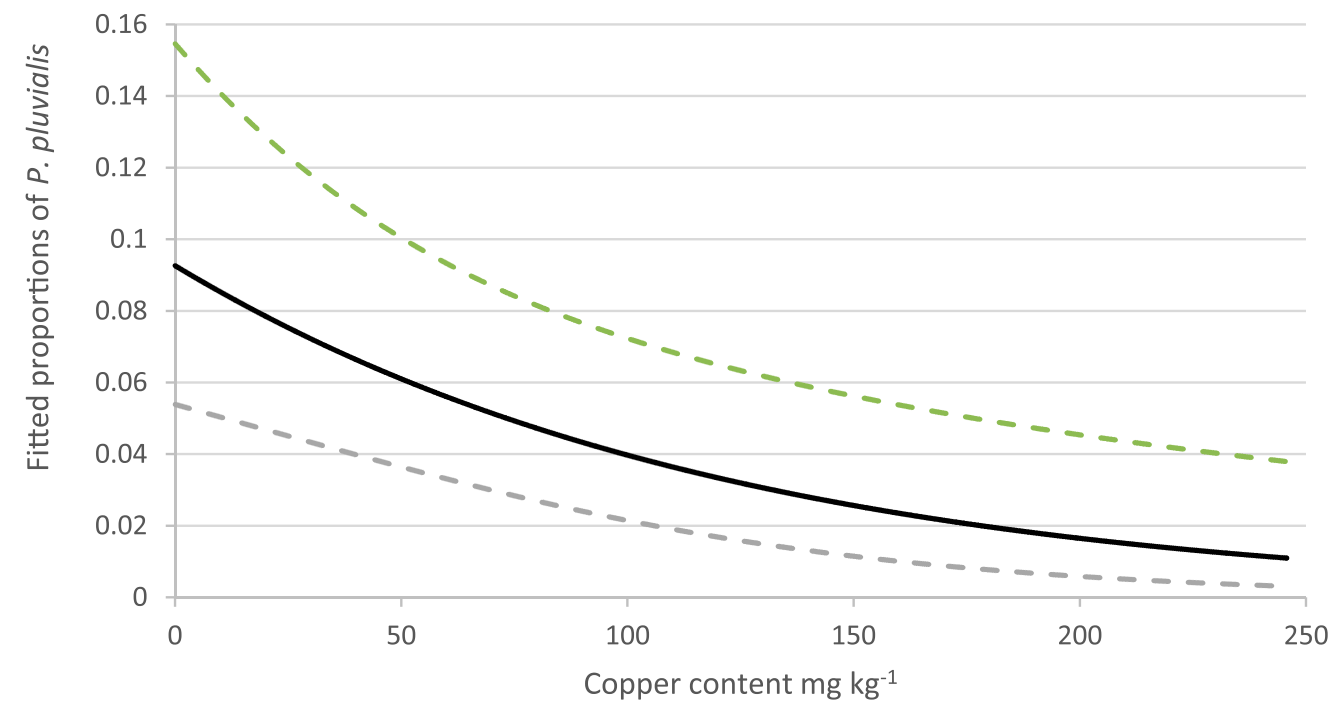

Fig. 5. Fitted proportions of Phytophthora pluvialis needles with lesions in experiment 3 as a function of surface copper content at the time of infection with predicted $95 \%$ confidence intervals based on the fitted model. 
that any second application of copper should be applied 2 to 3 months after the original spray.

These results have shown that copper is effective at reducing the symptoms of red needle cast on $P$. radiata. Our study provides the foundation for the development of a cost-effective management tool for red needle cast and motivates future research into the optimization of dose, timing, and frequency of application. Fieldbased observations show inoculum production and disease build up from late autumn to late spring (May to October), with inoculum build up early in the season likely to be a significant factor in disease impact under conditions favoring disease. Based on the results of this study, treatment may be optimized to enable timely inoculum knockdown and further refinement of application regimes. Infection criteria or thresholds of infection to inform spraying, however, will need to be determined from field studies and detailed epidemiological models. Using existing technologies and under current environmental conditions, the aerial application of copper for control of Dothistroma needle blight in New Zealand has been shown to pose a low risk to the receiving aquatic environment (Baillie et al. 2017). However, the impact of additional sprays for protection of trees from red needle cast on beneficial fungi and bacteria would need to be determined in future trials. Optimized spray timing is critical for the development of costeffective and responsible implementation of integrated pest management for red needle cast.

\section{Acknowledgments}

The authors acknowledge Caro Gous, Catherine Banham, and Stefan Gous (HeliResources) for technical and scientific input into the design and maintenance of these trials.

\section{Literature Cited}

American Society of Agricultural and Biological Engineers. 2009. ASABE-S-572, Spray Nozzle Classification by Droplet Spectra. American Society of Agricultural and Biological Engineers, St. Joseph, MI.

Babadoost, M., Pavon, C., Islam, S. and Tian, D. 2015. Phytophthora blight (Phytophthora capsici) of pepper and its management. Acta Hortic.: 61-66.

Baillie, B. R., Evanson, A. W., Unsworth, D., and Jeram, S. 2017. Aerial application of copper for Dothistroma control in New Zealand's planted forests-effect on stream environments. Environ. Sci. Pollut. Res. 24: 24494-24508.

Benjamini, Y., and Hochberg, Y. 1995. Controlling the false discovery rate: A practical and powerful approach to multiple testing. J. R. Stat. Soc. Ser. B 57:289-300.

Bulman, L., and Carlson, C. 2011. An aerial spray trial to test new mixes for control of Dothistroma needle blight. Page 18 in: Client report 48213. Scion, New Zealand Forest Research Institute, Rotorua, New Zealand.

Bulman, L., Dick, M., Ganley, R., McDougal, R., Schwelm, A., and Bradshaw, R. 2013. Dothistroma needle blight. Page 436 in: Infectious Forest Diseases. G. Nicolotti and P. Gonthier, eds. CABI, Wallingford, UK.

Bulman, L. S., Bradshaw, R. E., Fraser, S., Martïn-Garcïa, J., Barnes, I., Musolin, D. L., La Porta, N., Woods, A. J., Diez, J. J., Koltay, A., Drenkhan, R., Ahumada, R., Poljakovic-Pajnik, L., Queloz, V., Piškur, B., Doğmuş-Lehtijïrvi, H. T., Chira, D., Tomešovï-Haataja, V., Georgieva, M., Jankovskï, L., Anselmi, N., Markovskaja, S., Papazova-Anakieva, I., Sotirovski, K., Lazarević, J., Adamčikovï, K., Boroń, P., Braganïa, H., Vettraino, A. M., Selikhovkin, A. V., Bulgakov, T. S., and Tubby, K. 2016. A worldwide perspective on the management and control of Dothistroma needle blight. For. Pathol. 46:472-488.

Coelho, V., Coutinho, S., and Gouveia, M. E. 2005. Sensitivity to copper and phosphite of Phytophthora species associated with ink diseases of chestnut. Acta Hortic. 693:641-644.

Davis, R. A., Valentine, L. E., Craig, M. D., Wilson, B., Bancroft, W. J., and Mallie, M. 2014. Impact of Phytophthora-dieback on birds in Banksia woodlands in south west Western Australia. Biol. Conserv. 171:136-144.

Dick, M. A., Williams, N. M., Karl-Friedrich, M. B., Gardner, J. F., and Bulman, L. S. 2014. Pathogenicity of Phytophthora pluvialis to Pinus radiata and its relation with red needle cast disease in New Zealand. N. Z. J. For. Sci. 44:6.
Franich, R. A. 1988. Chemistry of weatthering and solubilisation of copper fungicide and the effect of copper on germination, growth, metabolism and reproduction of Dothistroma pini. N. Z. J. For. Sci. 18:318-328.

Franich, R. A., and Wells, L. G. 1975. The Chemistry of Weathering of Copper Fungicide on Pinus radiata Foliage and the Fungitoxicity of Coppe Residues to Dothistroma pini. New Zealand Institute of Forest Research, Rotorua, New Zealand.

Giannousi, K., Avramidis, I., and Dendrinou-Samara, C. 2013. Synthesis, characterization and evaluation of copper based nanoparticles as agrochemicals against Phytophthora infestans. RSC Advances 3:21743-21752.

Gilmour, J. W., and Noorderhaven, A. 1973. Control of Dothistroma needle blight by low volume aerial application of fungicides. N. Z. J. For. Sci. 3: $120-136$

Guenthner, J. F., Michael, K. C., and Nolte, P. 2001. The economic impact of potato late blight on US growers. Potato Res. 44:121-125.

Halsall, D. 1977. Effects of certain cations on the formation and infectivity of Phytophthora zoospores. 2. Effects of copper, boron, cobalt, manganese, molybdenum and zinc ions. Can. J. Microbiol. 23:1002-1010.

Hislop, E. C., and Cox, T. W. 1970. Local redistribution of fungicides on leaves by water. Ann. Appl. Biol. 66:89-101.

Hood, I., Gardner, J., Brownlie, R., Wright, L., Morrow, B., and Gare, M. 2017. Client report. Page 45 in: Infection Period of Red Needle Cast on Pinus radiata: Fourth Phase (2015-2017). New Zealand Forest Research Institute Ltd., Rotorua, New Zealand.

Hothorn, T., Bretz, F., and Westfall, P. 2008. Simultaneous inference in general parametric models. Biom. J. 50:346-363.

Lawrence, S. A., Armstrong, C. B., Patrick, W. M., and Gerth, M. L. 2017. Highthroughput chemical screening identifies compounds that inhibit different stages of the Phytophthora agathidicida and Phytophthora cinnamomi life cycles. Front. Microbiol. 8:1340.

Lucero, G., Boiteux, J., Pizzuolo, P., and Hapon, M. V. 2014. Effect of copper, zinc and potassium phosphites on the mycelium growth of Phytophthora nicotianae in olive tree dry branch disease. Acta Hortic. 437-442.

MacBean, C. 2016. The Pesticide Manual, 16th ed. British Crop Protection Council, Hampshire, UK.

Micron Sprayers Ltd. 2014. Ulva+: A Low Volume Sprayer for Crop Protection. Micron Sprayers Ltd., Bembridge Fort, Sandown, Isle of Wight, UK.

Morton, V., and Staub, T. 2008. A short history of fungicides. APSnet Features doi:10.1094/APSnetFeature-2008-0308

NZFOA. 2016. Facts and Figures. New Zealand Forest Owners Association, Inc, Wellington. www.nzfoa.org.nz. Accessed 4 August 2019.

Pinheiro, J., Bates, D., DebRoy, S., and Sarkar, D. 2015. Linear and nonlinear mixed effects models. R package version 3.1-119. https://cran.r-project.org/ src/contrib/Archive/nlme/nlme_3.1-119.tar.gz

R Core Team. 2016. R: A Language and Environment for Statistical Computing. R Foundation for Statistical Computing, Vienna, Austria.

Reeser, P., Sutton, W., and Hansen, E. M. 2013. Phytophthora pluvialis, a new species from mixed tanoak-Douglas-fir forests of western Oregon, U.S.A. N. Am. Fungi 8:1-8.

Ripley, B., Venables, B., Bates, D., Hornik, K., Gebhardt, A., and Firth, D. 2015. MASS: Support functions and datasets for venables and Ripleys MASS. R package version 7.3-5.0, ed.

Rolando, C., Dick, M. A., Gardner, J., Bader, M. K.-F., and Williams, N. 2017a Chemical control of two Phytophthora species infecting the canopy of Monterey Pine (Pinus radiata). For. Pathol. 7:e12327.

Rolando, C. A., Gaskin, R., Horgan, D., Williams, N., and Bader, M.-K. 2014. The use of adjuvants to improve uptake of phosphorous acid applied to Pinus radiata needles for control of foliar Phytophthora diseases. N. Z. J. For. Sci. 44:8.

Rolando, C. A., Gaskin, R. E., Gous, S. F., Horgan, D. B., and Raymond, L. G. $2017 \mathrm{~b}$. The effect of formulation, dose, and adjuvants on uptake of phosphite into pine foliage. Plant Dis. 101:1652-1658.

Skaug, H., Fournier, D., Nielsen, A., Magnusson, A., and Bolker, B. 2015. glmmADMB: Generalised linear mixed models using AD model Builder. R package version 0.8.1.

Venables, W. N. and Ripley, B. D. 2002. Modern Applied Statistics with S. Fourth Edition. Springer, New York.

Vettraino, A. M. 2010. Integrated Control Protocol (ICP) of ink disease of chestnut in central Italy: Principles and future perspectives. Acta Hortic. 425-430.

Zuur, A. F., Leno, E. N., Walker, N. J., Saveliev, A. A., and Smith, G. M. 2009. Mixed Effects Models and Extensions in Ecology With R. Springer, New York, NY. 